\title{
Emissão de dióxido de carbono após aplicação de dejetos líquidos e cama sobreposta de suínos
}

\author{
Sandro José Giacomini(1) e Celso Aita(1) \\ (1)Universidade Federal de Santa Maria, Centro de Ciências Rurais, Departamento de Solos, CEP 97105-900 Santa Maria, RS. E-mail: \\ sjgiacomini@smail.ufsm.br, caita@smail.ufsm.br
}

\begin{abstract}
Resumo - O objetivo deste trabalho foi avaliar a emissão de dióxido de carbono, após a aplicação ao solo de dejetos líquidos e cama sobreposta de suínos, na presença de palha de aveia, com e sem incorporação ao solo. $\mathrm{O}$ experimento foi conduzido em Argissolo Vermelho distrófico arênico. O delineamento utilizado foi o inteiramente casualizado, com três repetições. Os tratamentos consistiram da aplicação ou não de dejetos líquidos e cama sobreposta de suínos sobre palha de aveia, com e sem incorporação ao solo. Após a aplicação dos tratamentos, iniciou-se a medida da emissão de $\mathrm{CO}_{2}$, continuamente, pelo período de 120 dias. A incorporação dos dejetos de suínos e da palha ao solo aumenta a emissão de $\mathrm{CO}_{2}$ para a atmosfera, em comparação à distribuição desses materiais orgânicos na superfície do solo. A aplicação conjunta dos dejetos líquidos e da cama sobreposta de suínos com a palha não aumenta a emissão de $\mathrm{CO}_{2}$ para a atmosfera, o que indica que esses materiais orgânicos não favorecem a mineralização do carbono presente na palha de aveia.
\end{abstract}

Termos para indexação: mineralização, palha, plantio direto, preparo reduzido.

\section{Carbon dioxide emission after application of pig slurry and pig deep-litter}

\begin{abstract}
The objective of this work was to evaluate the carbon dioxide emission to atmosphere after pig slurry and deep-litter application to the soil, along with oat straw with and without soil incorporation. The experiment was carried out on a Hapludalf. The experimental design was a completely randomized one with three replicates. The treatments consisted of application, or not, of pig slurry and pig deep-litter on oat straw, with and without soil incorporation. The measurement of the $\mathrm{CO}_{2}$ emission began after treatment applications and lasted 120 days. Pig manure and oat straw incorporation to the soil increase $\mathrm{C}-\mathrm{CO}_{2}$ emission to the atmosphere, compared to the distribution of those organic materials on soil surface. Pig slurry and pig deep-litter application on the straw do not increase $\mathrm{CO}_{2}$ emission to the atmosphere, which indicates that these organic materials do not influence $\mathrm{C}$ mineralization present in oat straw.
\end{abstract}

Index terms: mineralization, straw, no-tillage, minimum tillage.

\section{Introdução}

Na Região Sul do Brasil, é cada vez mais freqüente a aplicação de dejetos de suínos ao solo, com resíduos culturais de cereais pobres em N (Aita et al., 2006), o que pode favorecer a mineralização do carbono desses resíduos, e contribuir para aumentar a emissão de $\mathrm{CO}_{2}$ para a atmosfera. Considerando-se que esse efeito pode variar com o tipo de preparo do solo, é necessário intensificar os estudos para comparar a emissão de $\mathrm{CO}_{2}$ após a aplicação de dejetos de suínos, com e sem preparo do solo.

Os sistemas de preparo do solo afetam a decomposição de palhas de cereais por alterar diferentemente as condições de contato entre o solo e a palha, os fatores abióticos do meio (temperatura e umidade) e a distribuição dos nutrientes no solo. Solos sob sistema de plantio direto (SPD), em que os resíduos culturais permanecem na superfície, apresentam menores variações de temperatura e maiores teores de umidade, comparados aos solos com revolvimento, seja por meio do preparo convencional ou preparo reduzido. Embora as condições abióticas no SPD sejam favoráveis à atividade microbiana no solo, a manutenção da palhada dos cereais na superfície reduz o contato entre os resíduos culturais e o solo e, também, as possibilidades de colonização do substrato pelos microrganismos e a disponibilidade de $\mathrm{N}$ para a decomposição, além de criar 
condições abióticas desfavoráveis junto aos resíduos (Angers \& Recous, 1997). A combinação desses fatores resulta em uma menor quantidade de $\mathrm{C}$ mineralizado das palhas de cereais no SPD, comparado aos sistemas de preparo com incorporação desses resíduos culturais ao solo (Coppens, 2005).

Durante a decomposição de resíduos culturais de cereais no solo, uma parte do C contido neles é assimilada pela biomassa microbiana, e outra parte é mineralizada na forma de $\mathrm{CO}_{2}$. Conjuntamente à assimilação do $\mathrm{C}$, ocorre a assimilação do $\mathrm{N}$ pela biomassa, a fim de suprir suas demandas desse nutriente para a biossíntese celular. Considerando-se que as palhas de cereais são pobres em $\mathrm{N}$ (alta $\mathrm{C} / \mathrm{N}$ ), parte desse $\mathrm{N}$ será suprido pelo solo. Caso a disponibilidade de $\mathrm{N}$ no solo seja limitada, a velocidade de decomposição da palha será reduzida. Essa relação existente entre os ciclos de $\mathrm{C}$ e $\mathrm{N}$ indica que a velocidade de decomposição das palhas de cereais é controlada pela disponibilidade de nitrogênio (Recous et al., 1995). Assim, a adição de N, via dejetos de suínos com a palha, poderá resultar em aumento na decomposição dessa palha (Saviozzi et al., 1997; Chantigny et al., 2001), principalmente em solos com baixa disponibilidade de N. Pelo fato de a incorporação favorecer o acesso dos microrganismos ao $\mathrm{C}$ da palha, espera-se que, nesse sistema, a adição de $\mathrm{N}$ via dejetos de suínos favoreça a decomposição da palha em maior grau do que no sistema com a palha mantida na superfície do solo.

$\mathrm{O}$ elevado volume de dejetos líquidos gerados pela suinocultura, aliado ao desenvolvimento dessa atividade em regiões que apresentam áreas agrícolas com topografia desfavorável ao uso dos dejetos, potencializa o impacto negativo dessa atividade sobre o ambiente. Uma das alternativas para a redução da quantidade de dejetos gerados na suinocultura consiste na criação de suínos em sistema de cama sobreposta (Kermarrec, 1999). Nesse sistema, os suínos podem permanecer durante todas as fases do processo criatório sobre uma cama que pode ser de maravalha, casca de arroz, palha de cereais ou serragem. A capacidade que esses materiais têm de absorver fezes, urina e água proporciona decomposição parcialmente aeróbia e provoca diminuição no volume de dejetos e geração de composto orgânico. Nas condições do Sul do Brasil, onde o uso da cama sobreposta está sendo mais difundido, é necessário avaliar o efeito desse composto orgânico sobre a emissão de $\mathrm{CO}_{2}$ para a atmosfera.
O objetivo deste trabalho foi avaliar a emissão de $\mathrm{CO}_{2}$, após a aplicação ao solo de dejetos líquidos e cama sobreposta de suínos, na presença de palha de aveia, com e sem incorporação ao solo.

\section{Material e Métodos}

O trabalho foi realizado de outubro de 2002 a março de 2003, na área experimental do Departamento de Solos, da Universidade Federal de Santa Maria, na região central do Estado do Rio Grande do Sul. O solo da área é classificado como Argissolo Vermelho distrófico arênico (Embrapa, 1999), com textura superficial francoarenosa no horizonte A e franco-argilosa no horizonte B. Na caracterização da área, determinaram-se os teores de argila e de matéria orgânica da camada $0-10 \mathrm{~cm}$ do solo, cujos valores foram de $150 \mathrm{~g} \mathrm{~kg}^{-1}$ e $18 \mathrm{~g} \mathrm{~kg}^{-1}$, respectivamente.

Os tratamentos foram dispostos em delineamento inteiramente casualizado, com três repetições, em esquema fatorial $3 \times 2$. Os fatores avaliados foram: três materiais orgânicos (palha, palha + dejetos líquidos de suínos e palha + cama sobreposta de suínos) e dois modos de aplicação (incorporado e superfície do solo). As unidades experimentais constituíram-se de duas câmaras estáticas, no interior das quais foram aplicados os seguintes tratamentos: T1, palha de aveia-preta (Avena strigosa Schieb.) na superfície do solo; T2, palha de aveia incorporada ao solo; T3, palha de aveia e dejetos líquidos na superfície do solo; T4, palha de aveia e dejetos líquidos incorporados ao solo; T5, palha de aveia e cama sobreposta, na superfície do solo; e T6, palha de aveia e cama sobreposta incorporados ao solo.

A palha de aveia-preta foi coletada quando a planta se encontrava no estádio de maturação fisiológica. Após a coleta, o material foi secado ao ar e mantido em ambiente seco até sua utilização, quando uma subamostra foi colocada em estufa a $65^{\circ} \mathrm{C}$, para obtenção do teor de matéria seca (MS). A determinação da MS foi realizada, a fim de calcular a quantidade de palha secada ao ar, a ser adicionada em cada câmara, para atingir o equivalente a $3,6 \mathrm{Mg} \mathrm{ha}^{-1}$ de matéria seca $\left(65^{\circ} \mathrm{C}\right)$. $\mathrm{O}$ material secado a $65^{\circ} \mathrm{C}$ foi moído em um triturador de forragens, subamostrado e moído novamente em moinho Wiley. No material seco e moído, foram determinados os teores de nitrogênio total $(\mathrm{N})$ e carbono orgânico (C), conforme Tedesco et al. (1995).

Os dejetos utilizados foram obtidos em dois sistemas distintos de criação de suínos - sistema convencional e 
em cama sobreposta. No sistema convencional, os dejetos líquidos, obtidos de animais de maternidade e recria, eram compostos de fezes, urina, sobras de alimentação e de água dos bebedouros, água das chuvas, pêlos e poeira. A cama sobreposta foi coletada após terem sido criados cinco lotes de suínos de terminação (15 meses) sobre uma cama de maravalha. A cama sobreposta era composta por fezes, urina, pêlos, poeira, sobra de ração, água dos bebedouros e maravalha.

A matéria seca dos dejetos líquidos e da cama sobreposta foi determinada após a secagem dos dejetos em estufa a $65^{\circ} \mathrm{C}$ até peso constante. No material secado e moído, foram determinados os teores de C orgânico (Tedesco et al., 1995). Nos dejetos líquidos, os teores de $\mathrm{N}$ total e de $\mathrm{N}$ amoniacal $\left(\mathrm{N}_{-} \mathrm{NH}_{4}{ }^{+}+\mathrm{N}-\mathrm{NH}_{3}\right)$ foram determinados sem secagem prévia, conforme Aita et al. (2006). Na cama sobreposta úmida, os teores de $\mathrm{N}$ total,

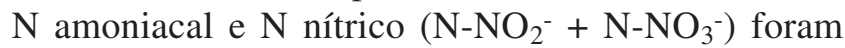
determinados em $1 \mathrm{~g}$ de material, conforme Tedesco et al. (1995). Nos dejetos líquidos, a determinação do $\mathrm{pH}$ foi realizada diretamente em uma alíquota de cerca de $60 \mathrm{~mL}$ de dejetos, enquanto na cama sobreposta, o pH em água foi determinado na mistura de dejetos e água destilada na proporção de 1:1 (Tedesco et al., 1995). As características químicas e a quantidade adicionada de palha, dejetos líquidos e cama sobreposta estão apresentadas na Tabela 1.

As quantidades de dejetos líquidos e de cama sobreposta de suínos foram equivalentes à aplicação de $140 \mathrm{~kg} \mathrm{ha}^{-1}$ de $\mathrm{N}$ total, correspondentes às doses de 63,6 $\mathrm{m}^{3} \mathrm{ha}^{-1}$ e $13,2 \mathrm{Mg} \mathrm{ha}^{-1}$, respectivamente. Essas doses foram baseadas na análise da concentração do $\mathrm{N}$ total dos dejetos (Tabela 1), efetuada anteriormente à sua aplicação no campo.

A emissão de $\mathrm{CO}_{2}$ foi medida continuamente, durante 120 dias, tendo-se empregado câmaras estáticas (Aita et al., 2006). As câmaras foram construídas a partir de tubos de cloro polivinil (PVC), com diâmetro de $0,30 \mathrm{~m}$, cuja parte superior é revestida com uma borracha para facilitar sua completa vedação pela tampa, o que impede trocas gasosas com a atmosfera externa. A tampa é constituída de chapa de zinco galvanizado, fixada ao cilindro de PVC por meio de quatro parafusos externos, distribuídos simetricamente em sua circunferência. Sobre a tampa, foi colada uma camada de isopor (1,5 cm de espessura), a fim de evitar oscilações bruscas na temperatura interna das câmaras. No interior da câmara e à altura de $7 \mathrm{~cm}$ da superfície do solo, foi instalada uma armação em ferro, em forma de $X$, para suportar o recipiente de plástico $(4 \mathrm{~cm}$ de altura e diâmetro interno de $10 \mathrm{~cm}$ ), com $100 \mathrm{~mL}$ da solução de $\mathrm{NaOH} 1 \mathrm{~mol} \mathrm{~L}^{-1}$, utilizada para captar o $\mathrm{CO}_{2}$ evoluído.

Para a instalação de cada câmara, em total de 36, foram retirados da superfície do solo todos os resíduos vegetais remanescentes de culturas anteriores. Os cilindros dos tratamentos sem incorporação apresentavam $30 \mathrm{~cm}$ de altura e foram inseridos no solo até a profundidade de $5 \mathrm{~cm}$. Logo após a instalação dos cilindros, foi adicionada a palha de aveia na superfície do solo. Os dejetos líquidos foram distribuídos sobre a palha com auxílio de um recipiente de plástico, com capacidade para $1 \mathrm{~L}$, no qual foi acoplada a extremidade de um regador.

Nos tratamentos com incorporação, utilizaram-se cilindros com $40 \mathrm{~cm}$ de altura inseridos no solo até a profundidade de $15 \mathrm{~cm}$. Para realizar a incorporação da palha, primeiramente foi removido da área onde seria instalada a câmara, o solo da camada superficial $(8 \mathrm{~cm}$ de profundidade). Esse solo foi colocado sobre uma lona e misturado manualmente com a palha ou palha + dejetos líquidos e cama sobreposta. A mistura do solo com os resíduos orgânicos foi colocada, a seguir, no local de onde havia sido retirado o solo, e os cilindros foram

Tabela 1. Quantidades adicionadas ao solo relativas à matéria seca (MS), carbono (C) e nitrogênio (N) e composição química dos dejetos líquidos, cama sobreposta e palha de $\operatorname{aveia}^{(1)}$.

\begin{tabular}{|c|c|c|c|c|c|c|c|c|}
\hline Resíduo orgânico & MS & $\mathrm{C}$ & $\mathrm{N}$ total & $\mathrm{N}$ amoniacal & N nítrico & $\mathrm{N}$ orgânico & $\mathrm{C} / \mathrm{N}$ & $\mathrm{pH}$ \\
\hline \multicolumn{9}{|c|}{ 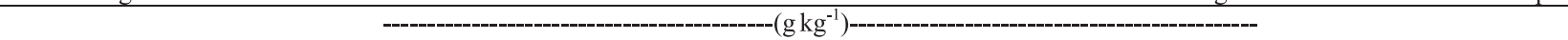 } \\
\hline Dejetos líquidos & 46 & 9,7 & 2,2 & 0,91 & - & 1,29 & 4,4 & 7,8 \\
\hline Cama sobreposta & 477 & 109,7 & 10,6 & 1,12 & 0,04 & 9,44 & 10,3 & 9,1 \\
\hline Palha de aveia & - & 425,3 & 10,4 & - & - & - & 40,9 & - \\
\hline \multicolumn{9}{|c|}{ 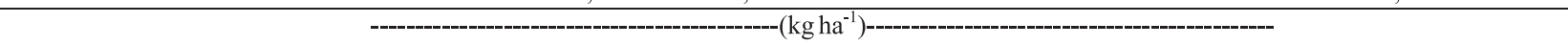 } \\
\hline Dejetos líquidos & 2.925 & 617 & 140 & 57,9 & - & 82,1 & & \\
\hline Cama sobreposta & 6.296 & 1.448 & 140 & 14,8 & 0,53 & 124,6 & & \\
\hline Palha de aveia & 3.600 & 1.531 & 37 & - & - & - & & \\
\hline
\end{tabular}

${ }^{(1)}$ Os valores de MS, C e N referem-se à base úmida. 
inseridos. A palha foi cortada em pedaços de $20 \mathrm{~cm}$, para facilitar seu acondicionamento no interior das câmaras. O tempo decorrido desde a retirada do solo até a instalação das câmaras, nos tratamentos com incorporação, foi de aproximadamente 4 min. A adição dos dejetos líquidos e da cama sobreposta ocorreu simultaneamente nos tratamentos com e sem incorporação ao solo.

Próximo ao conjunto de 36 câmaras, foi instalada câmara com fundo vedado, que recebia somente o recipiente com $\mathrm{NaOH}$ e era utilizada para determinar a quantidade de $\mathrm{C}$ do $\mathrm{CO}_{2}\left(\mathrm{C}-\mathrm{CO}_{2}\right)$ presente no ar (prova em branco), em cada avaliação realizada.

Logo após a aplicação dos tratamentos, teve início a determinação da evolução de $\mathrm{CO}_{2}$, que foi realizada alternadamente nas duas câmaras de cada unidade experimental. Enquanto uma câmara ficava hermeticamente fechada, para a captação do $\mathrm{CO}_{2}$ emitido, a outra câmara permanecia aberta. Este procedimento teve por objetivo diminuir a interferência das câmaras sobre as condições ambientais ocorridas durante o experimento e, conseqüentemente, sobre o processo de decomposição dos materiais orgânicos no solo. A frequiência para a troca da solução de $\mathrm{NaOH}$ foi diária durante a primeira semana e, a partir desse período, variou conforme a intensidade da atividade microbiana. O excesso de $\mathrm{NaOH}$ em cada coleta foi titulado com $\mathrm{HCl} 1 \mathrm{~mol} \mathrm{~L}^{-1}$ (Stotzky, 1965).

Sempre que possível, após a ocorrência de chuvas, era efetuada a troca da solução receptora. As câmaras que estavam abertas durante a chuva recebiam uma nova solução, e naquelas câmaras que estavam fechadas, era adicionada água destilada. Como o movimento lateral de água das precipitações provocava o umedecimento de parte do solo do interior dos cilindros, optou-se por adicionar, após cada precipitação, apenas um terço do seu volume total, medido em pluviômetros instalados junto ao experimento.

O fluxo de C-CO ${ }_{2}\left(\mathrm{~F}_{\mathrm{C}-\mathrm{CO}_{2}}, \mathrm{~kg} \mathrm{ha}^{-1} \mathrm{~h}^{-1}\right)$ para a atmosfera, em cada intervalo de coleta, foi calculado a partir da seguinte equação:

$\mathrm{F}_{\mathrm{C}-\mathrm{CO}_{2}}=\frac{[(\mathrm{QC}-\mathrm{QCb}) \times 10]}{(\mathrm{A} \times \mathrm{t})}$,

em que QC é a quantidade de $\mathrm{C}-\mathrm{CO}_{2}$ dos tratamentos; $\mathrm{QCb}$ é a quantidade de $\mathrm{C}-\mathrm{CO}_{2}$ captada pela solução de $\mathrm{NaOH}$, na prova em branco; $\mathrm{A}$ é a área da câmara $\left(\mathrm{m}^{2}\right)$; e t é o intervalo de tempo (horas) entre duas avaliações.
A quantidade de $\mathrm{C}-\mathrm{CO}_{2}$, emitida entre duas coletas, foi obtida pela multiplicação de $\mathrm{F}_{\mathrm{C}-\mathrm{CO}_{2}}$ pelo tempo em horas, transcorrido durante essas coletas. A quantidade acumulada de $\mathrm{C}-\mathrm{CO}_{2}$, em cada tratamento, foi obtida pela soma das quantidades de $\mathrm{C}-\mathrm{CO}_{2}$ de cada coleta.

A emissão de $\mathrm{CO}_{2}$ foi medida entre as fileiras da cultura do milho, que foi semeado manualmente logo após a instalação das câmaras no campo. Assim, o $\mathrm{CO}_{2}$ medido é oriundo da decomposição dos materiais orgânicos adicionados ao solo (palha e dejetos), da matéria orgânica do solo (MOS) e da respiração das raízes do milho. Na fase inicial do experimento, a contribuição das raízes na emissão de $\mathrm{CO}_{2}$ é nula e aumenta com o desenvolvimento da cultura.

Os dados relativos à mineralização acumulada de $\mathrm{C}$ foram interpretados pela análise da variância, segundo esquema fatorial $3 \times 2$, correspondente aos três materiais orgânicos e dois modos de aplicação. Como não houve interação significativa, entre os dois fatores avaliados, sobre a quantidade de $\mathrm{C}$ acumulada, os efeitos principais dos fatores foram analisados separadamente, pela comparação das médias de tratamentos pelo teste de Tukey a $5 \%$ de probabilidade de erro. Para os dados relativos aos de fluxos de $\mathrm{C}-\mathrm{CO}_{2}$, foi calculado, em cada data de avaliação, o erro-padrão da média.

\section{Resultados e Discussão}

Não houve interação entre os fatores materiais orgânicos - palha, dejetos líquidos e cama sobreposta e os modos de aplicação - superfície e incorporados -, sobre a quantidade total de $\mathrm{C}-\mathrm{CO}_{2}$, emitida durante o período de avaliação. Houve apenas efeito isolado da modalidade de aplicação dos materiais orgânicos.

A incorporação dos dejetos de suínos e da palha ao solo aumentou a emissão de $\mathrm{CO}_{2}$ para a atmosfera, em relação à permanência desses materiais na superfície do solo (Figura $1 \mathrm{~A}$ ). Esse aumento na emissão de $\mathrm{CO}_{2}$ ocorreu desde o início do experimento, pois, na primeira avaliação, realizada após 4 horas, o fluxo de $\mathrm{C}-\mathrm{CO}_{2}$ dos tratamentos, com a incorporação dos materiais orgânicos, superou em $1,99 \mathrm{~kg} \mathrm{ha}^{-1} \mathrm{~h}^{-1}$ o fluxo de C-CO $\mathrm{CO}_{2}$ dos tratamentos em que esses mesmos materiais foram mantidos na superfície do solo. Esse fluxo inicial de $\mathrm{CO}_{2}$, possivelmente, não tem origem unicamente na decomposição microbiana dos compostos carbonados presentes no solo. Reicosky \& Archer (2007) atribuíram essa rápida emissão de $\mathrm{CO}_{2}$ para a atmosfera, logo após o preparo do solo, à liberação do $\mathrm{CO}_{2}$ aprisionado no 
interior do solo. Após a liberação inicial, o $\mathrm{CO}_{2}$ medido tem origem na mineralização do $\mathrm{C}$ presente nos dejetos, na palha e na matéria orgânica do solo (MOS).

A partir dos fluxos de $\mathrm{CO}_{2}$ medidos durante os 120 dias, é possível separar as diferenças entre os tratamentos com e sem incorporação em três fases (Figura 1 A). A primeira, nos 30 dias iniciais, com maiores diferenças, quando a taxa média de emissão de $\mathrm{C}-\mathrm{CO}_{2}$ nos tratamentos com incorporação superou a dos tratamentos sem incorporação em $0,47 \mathrm{~kg} \mathrm{ha}^{-1} \mathrm{~h}^{-1}$ $\left(1,86 \mathrm{~kg} \mathrm{ha}^{-1} \mathrm{~h}^{-1}-1,39 \mathrm{~kg} \mathrm{ha}^{-1} \mathrm{~h}^{-1}\right)$. A segunda, entre 30 e 80 dias, quando os tratamentos com incorporação emitiram $0,21 \mathrm{~kg} \mathrm{ha}^{-1} \mathrm{~h}^{-1}$ de $\mathrm{C}-\mathrm{CO}_{2}$ a mais do que os
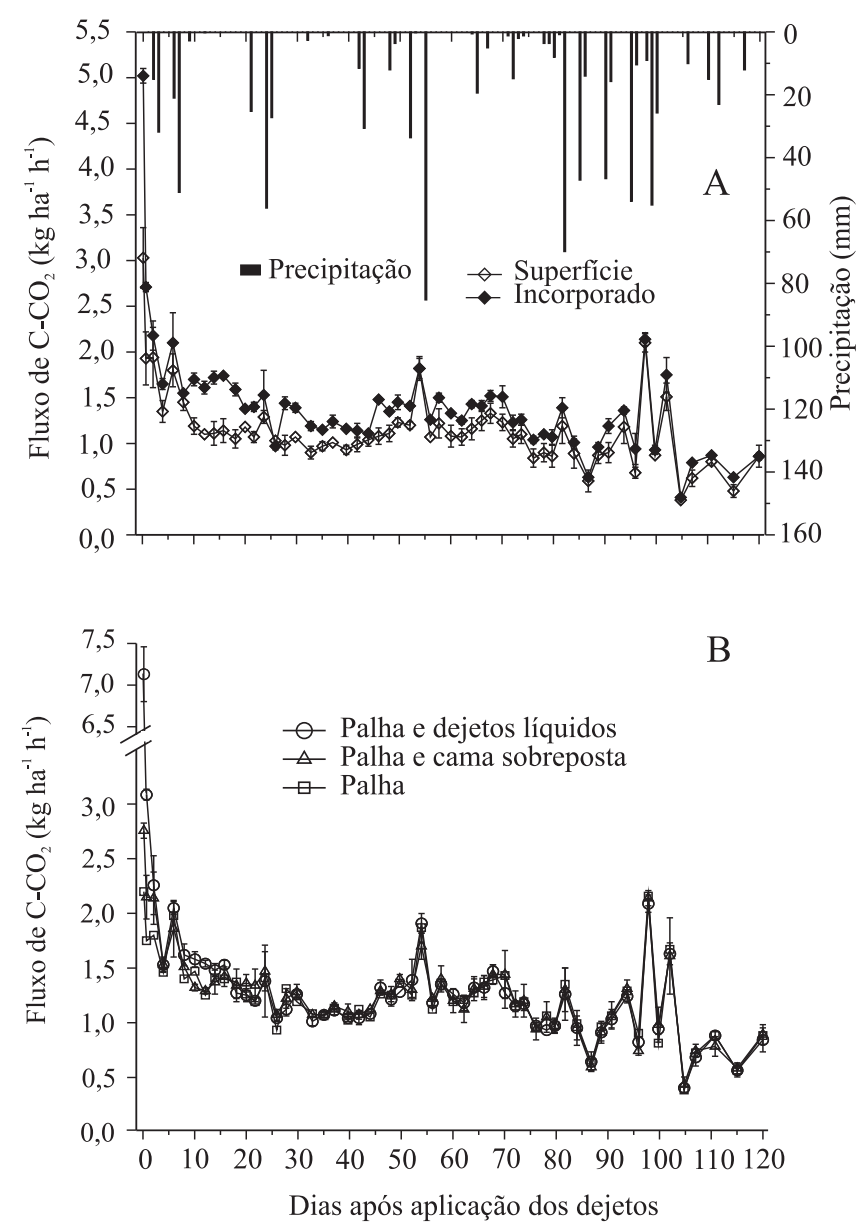

Figura 1. Fluxos de C-CO $\mathrm{CO}_{2}$ com os materiais orgânicos mantidos na superfície ou incorporados ao solo, na média dos tratamentos com palha, palha + dejetos líquidos e palha + cama sobreposta (A) e nos tramentos com palha, palha + dejetos líquidos e palha + cama sobreposta na média das duas modalidades de aplicação (B), e precipitação diária. Barras verticais, em cada avaliação do fluxo de $\mathrm{C}-\mathrm{CO}_{2}$, representam o desvio-padrão. tratamentos sem incorporação $\left(1,31 \mathrm{~kg} \mathrm{ha}^{-1} \mathrm{~h}^{-1}\right.$ - 1,10 $\left.\mathrm{kg} \mathrm{ha}^{-1} \mathrm{~h}^{-1}\right)$. Na última fase, dos 80 dias até o final da avaliação, a diferença na emissão de $\mathrm{C}-\mathrm{CO}_{2}$, em favor dos tratamentos com incorporação, diminuiu para $0,13 \mathrm{~kg} \mathrm{ha}^{-1} \mathrm{~h}^{-1}\left(1,06 \mathrm{~kg} \mathrm{ha}^{-1} \mathrm{~h}^{-1}-0,93 \mathrm{~kg} \mathrm{ha}^{-1} \mathrm{~h}^{-1}\right)$. Observa-se que, nas duas modalidades de aplicação dos materiais orgânicos no solo, as maiores emissões de $\mathrm{CO}_{2}$ ocorreram na fase inicial da decomposição. Tais resultados devem-se ao fato de que, na fase inicial, os microrganismos utilizam a fração orgânica mais biodegradável, principalmente aquela solúvel em água (Reinertsen et al., 1984). Após a decomposição dessa fração, aumenta gradativamente nos resíduos a proporção de compostos de difícil decomposição, como lignina e outros constituintes fenólicos recalcitrantes (Paul \& Clark, 1996).

A proximidade entre os fluxos das duas modalidades de aplicação dos materiais orgânicos ao solo esteve relacionada à ocorrência de chuvas. Observa-se que em períodos com baixa precipitação - 8 a 20 dias e 26 a 41 dias -, houve redução nos fluxos de C- $\mathrm{CO}_{2}$ (Figura 1). Esse efeito ocorreu, primeiramente, no sistema em que não houve incorporação dos resíduos ao solo. Nesse sistema, a população microbiana se localiza na residosfera, onde estão concentrados os resíduos culturais. Com a ocorrência de períodos de baixa precipitação, a deficiência de umidade na residosfera reduz a atividade microbiana e, consequientemente, a emissão de $\mathrm{CO}_{2}$ para a atmosfera. Aita et al. (2006) avaliaram a decomposição de palha de aveia em plantio direto e, também, verificaram que em períodos secos ocorreu redução na emissão de $\mathrm{CO}_{2}$ para a atmosfera, o que evidencia que a taxa de decomposição dos materiais orgânicos nesse sistema está intimamente relacionada aos ciclos de umedecimento e secagem do solo.

A aplicação de dejetos líquidos e da cama sobreposta de suínos aumentou o fluxo de $\mathrm{C}-\mathrm{CO}_{2}$ para a atmosfera, apenas nos primeiros dias após a aplicação desses materiais ao solo (Figura $1 \mathrm{~B}$ ). Na primeira avaliação realizada, verificou-se um pico na emissão de $\mathrm{C}-\mathrm{CO}_{2}$ no tratamento com dejetos líquidos, cujo valor superou aquele observado no solo do tratamento que recebeu a adição de apenas palha em $4,9 \mathrm{~kg} \mathrm{ha}^{-1} \mathrm{~h}^{-1}$. Depois, a emissão de $\mathrm{C}-\mathrm{CO}_{2}$ decresceu rapidamente, e na segunda avaliação, essa diferença já declinou para $1,34 \mathrm{~kg} \mathrm{ha}^{-1} \mathrm{~h}^{-1}$. Esse aumento na emissão de $\mathrm{CO}_{2}$, nas primeiras horas após a aplicação de dejetos líquidos de suínos ao solo, foi observado em outros trabalhos (Rochette et al., 2004; Aita et al., 2006) e é atribuído principalmente à liberação do $\mathrm{CO}_{2}$ dissolvido nos dejetos de suínos, e àquele formado 
a partir do $\mathrm{HCO}_{3}{ }^{-}$e $\mathrm{CO}_{3}{ }^{2-}$, gerados durante o armazenamento dos dejetos (Flessa \& Beese, 2000). Essas formas de carbono inorgânico, dissolvido nos dejetos, são constituídas a partir do $\mathrm{CO}_{2}$ produzido pela hidrólise da uréia e pela decomposição anaeróbia dos ácidos orgânicos voláteis, durante o armazenamento dos dejetos líquidos em esterqueira anaeróbica (Sommer \& Husted, 1995). Além disso, parte do $\mathrm{CO}_{2}$ emitido nessa fase pode ter origem da decomposição de compostos de baixo peso molecular, tais como ácidos graxos voláteis, que são produzidos durante a fermentação dos dejetos líquidos em esterqueiras anaeróbicas (Kirchmann \& Lundvall, 1993).

$\mathrm{O}$ fato de os fluxos de $\mathrm{C}-\mathrm{CO}_{2}$ do tratamento com dejetos líquidos terem sido semelhantes ao tratamento com o uso exclusivo de palha, já a partir do segundo dia de avaliação (Figura $1 \mathrm{~B}$ ), indica que a fração do $\mathrm{C}$ mais biodegradável foi utilizada pelos microrganismos na fase inicial de decomposição, e que sobraram compostos carbonados mais recalcitrantes. Esse resultado corrobora o obtido por Aita et al. (2006) que, em plantio direto, encontraram diferença de apenas $0,11 \mathrm{~kg} \mathrm{ha}^{-1} \mathrm{~h}^{-1}$ na emissão de $\mathrm{C}-\mathrm{CO}_{2}$, após 20 dias da aplicação dos dejetos líquidos de suínos sobre a palha de aveia, em relação ao tratamento sem dejetos. Chantigny et al. (2001) incorporaram os dejetos à palha e verificaram que os fluxos de $\mathrm{CO}_{2}$ superaram aqueles observados no tratamento sem dejetos, durante os 28 dias de avaliação. As diferenças obtidas, nesses estudos, devem estar ligadas ao regime de chuvas na fase inicial de decomposição dos dejetos e da palha. Neste trabalho, as chuvas acumuladas nos primeiros sete dias somaram $119 \mathrm{~mm}$, contra apenas $26 \mathrm{~mm}$ do trabalho de Chantigny et al. (2001). Este fato deve ter contribuído para lixiviar os compostos carbonados solúveis em água da palha e para facilitar sua decomposição, no início do experimento.

Com exceção da primeira avaliação, observa-se na Figura $1 \mathrm{~B}$ que o efeito da aplicação ao solo da cama sobreposta, sobre os fluxos de C- $\mathrm{CO}_{2}$, foi semelhante ao observado com os dejetos líquidos. Com a aplicação de ambos os materiais orgânicos com a palha, os fluxos de $\mathrm{C}-\mathrm{CO}_{2}$ superaram aqueles observados no tratamento apenas com palha, somente nos primeiros dias do experimento. Considerando-se que a quantidade de $\mathrm{C}$ adicionado ao solo com a cama sobreposta foi cerca de 2,3 vezes maior do que no tratamento com dejetos líquidos (Tabela 1), esperava-se maior efeito da cama sobreposta sobre a emissão de $\mathrm{CO}_{2}$. Esse resultado pode estar relacionado ao fato de que aproximadamente $70 \%$ do $\mathrm{C}$ presente na cama sobreposta estava contido na maravalha, cuja relação $\mathrm{C} / \mathrm{N}$ e o teor de lignina são elevados. Além disso, a cama sobreposta utilizada neste trabalho resultou da criação de cinco lotes de suínos num período de 15 meses. É provável que, durante a criação dos animais, grande parte dos compostos carbonados da cama foram degradados pelos microrganismos e compostos humificados de difícil decomposição foram formados, conforme observou Kermarrec (1999).

Ao fim de 120 dias, a incorporação dos materiais orgânicos ao solo aumentou a emissão de $\mathrm{C}-\mathrm{CO}_{2}$ para a atmosfera em $627 \mathrm{~kg} \mathrm{ha}^{-1}(18 \%)$, em relação à sua distribuição na superfície do solo (Figura 2 A). Tais

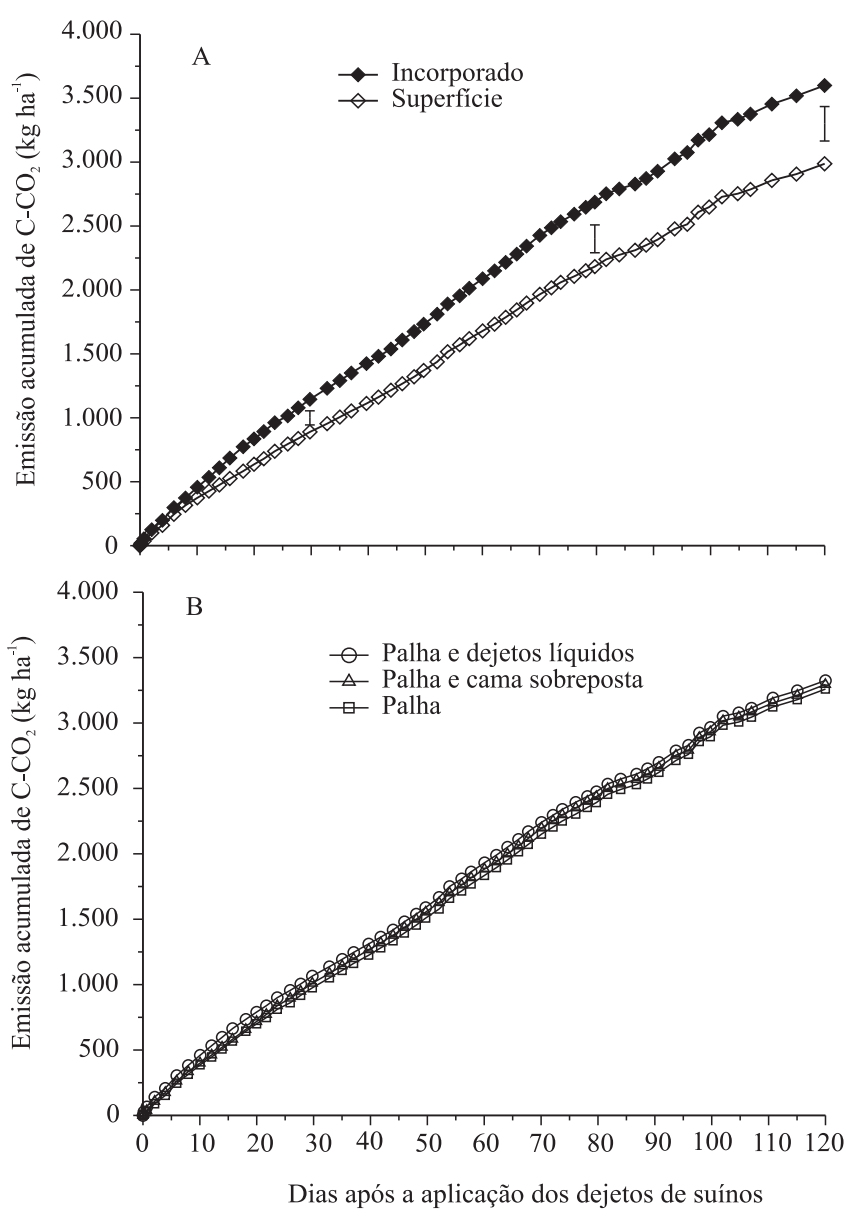

Figura 2. Emissão acumulada de $\mathrm{C}-\mathrm{CO}_{2}$ com os materiais orgânicos mantidos na superfície ou incorporados ao solo, na média dos tratamentos com palha, palha + dejetos líquidos e palha + cama sobreposta (A) e nos tramentos com palha, palha + dejetos líquidos e palha + cama sobreposta na média das duas modalidades de aplicação (B). Nas datas em que houve diferença significativa (Tukey a 5\% de probabilidade) entre as médias de cada tratamento, essas diferenças estão representadas pelas barras verticais. 
resultados indicam que a prática de incorporar os dejetos de suínos ao solo, como alternativa para reduzir as perdas de $\mathrm{N}$ por volatilização de amônia e o mau cheiro, aumenta a emissão de $\mathrm{CO}_{2}$ para a atmosfera, em comparação à aplicação dos mesmos materiais ao solo sem incorporação. Esse aumento na emissão de $\mathrm{CO}_{2}$, ocasionado pelo revolvimento do solo, está relacionado ao aumento da taxa de mineralização tanto do C da MOS como daquele adicionado com os dejetos e a palha. Em função da intensidade e da freqüência em que o solo é submetido ao revolvimento, poderá ocorrer redução no estoque de MOS a médio e longo prazo.

$\mathrm{O}$ fato de a emissão cumulativa de $\mathrm{C}-\mathrm{CO}_{2}$ não ter diferido entre os tratamentos com o uso exclusivo de palha, com palha + dejetos líquidos e com palha + cama sobreposta, tanto em superfície como incorporados ao solo (Figura 2 B), indica que tanto os dejetos líquidos como a cama sobreposta não favoreceram a mineralização do $\mathrm{C}$ presente na cama. Além disso, a matéria orgânica dos dejetos líquidos e, principalmente, da cama sobreposta foi pouco atacada pelos microrganismos, o que indica que o uso continuado desses materiais orgânicos poderá resultar em incremento no estoque de $\mathrm{C}$ do solo.

Esses resultados contrariam a hipótese de que o aumento da disponibilidade de $\mathrm{N}$ no solo, em conseqüência da aplicação de dejetos de suínos com a palha, favoreceria a mineralização do $\mathrm{C}$ da palha. Aita et al. (2006) aplicaram dejetos líquidos de suínos sobre duas palhas de aveia (relações $\mathrm{C} / \mathrm{N}$ de 43 e 45) em condições de campo, em plantio direto e, também, verificaram que os dejetos não afetaram a mineralização do $\mathrm{C}$ da palha. Esses resultados contrariam aqueles obtidos em condições de campo por Chantigny et al. (2001) e em condições de laboratório por Saviozzi et al. (1997). Chantigny et al. (2001) verificaram que, após 28 dias, o tratamento em que os dejetos foram incorporados ao solo com a palha de cevada $(\mathrm{C} / \mathrm{N}$ de 47,3 ), liberou $26 \%$ mais $\mathrm{C}-\mathrm{CO}_{2}$ do que a soma das quantidades de $\mathrm{C}-\mathrm{CO}_{2}$ liberadas pelos tratamentos com esses dois materiais orgânicos separadamente. Saviozzi et al. (1997) relatam um aumento de $23 \%$ na emissão de $\mathrm{CO}_{2}$, após 230 dias, quando dejetos de suínos e palha de trigo foram incubados conjuntamente a $25^{\circ} \mathrm{C}$. A maior relação $\mathrm{C} / \mathrm{N}$ da palha $(79,6)$ e sua moagem fina, no estudo de Saviozzi et al. (1997), e a baixa precipitação após a aplicação dos dejetos líquidos no estudo de Chantigny et al. (2001), devem ter contribuído para favorecer o efeito positivo dos dejetos líquidos sobre a decomposição da palha.
$\mathrm{O}$ fato de não ter sido encontrado sinergismo entre dejetos e palha, na emissão de $\mathrm{CO}_{2}$, se deve, provavelmente, às condições climáticas ocorridas na fase inicial do trabalho. Nos primeiros sete dias após a aplicação dos dejetos, a precipitação acumulada atingiu $119 \mathrm{~mm}$, dos quais $48 \mathrm{~mm}$ ocorreram nos primeiros três dias após a aplicação (Figura 1). É provável que esta quantidade elevada de água da chuva tenha favorecido a saída do $\mathrm{N}$ amoniacal da zona ativa de decomposição. $\mathrm{Se}$ o $\mathrm{N}$ aplicado pelos dejetos não permanecer nessa região, em contato com a palha, a velocidade de decomposição da palha não será afetada pela aplicação dos dejetos. Aita et al. (2006) também atribuíram à precipitação pluviométrica o fato de os dejetos líquidos de suínos, aplicados sobre a palha de aveia em plantio direto, não terem favorecido a decomposição da palha.

A ausência de efeito positivo do N, aplicado com os dejetos, sobre a mineralização do $\mathrm{C}$ da palha, pode ser atribuída também à relação $\mathrm{C} / \mathrm{N}$ da palha de aveia. Possivelmente, a relação $\mathrm{C} / \mathrm{N}$ de 40,9 da palha utilizada (Tabela 1) não seja suficientemente elevada, para que sua decomposição fosse favorecida pela adição de $\mathrm{N}$ por meio dos dejetos. É provável que a quantidade de $\mathrm{N}$ presente na palha tenha atendido a demanda em $\mathrm{N}$ dos microrganismos decompositores. Além disso, o N oriundo da mineralização da matéria orgânica do solo também pode ter contribuído para suprir as necessidades microbianas em nitrogênio.

A proximidade entre a emissão cumulativa de $\mathrm{C}-\mathrm{CO}_{2}$, nos tratamentos com palha e palha + cama sobreposta, indica que grande parte do $\mathrm{C}$ presente nesse material é de difícil decomposição. Conforme comentado anteriormente, esse resultado se deve à composição da cama sobreposta, a qual apresentava aproximadamente $70 \%$ do C na maravalha. Um aspecto interessante, a se avaliar em estudos futuros, envolve a comparação da decomposição no solo de diferentes tipos de camas utilizadas para a criação de suínos (maravalha, casca de arroz e palha de cereais), bem como de camas submetidas a diferentes tempos de permanência no sistema de criação.

Os resultados deste trabalho demonstram que a aplicação conjunta dos dejetos com a palha não aumenta a emissão de $\mathrm{CO}_{2}$ para a atmosfera, o que indica que os dejetos de suínos não favoreceram a mineralização do $\mathrm{C}$ presente na palha de aveia. Além disso, a emissão de $\mathrm{CO}_{2}$ para a atmosfera somente é maior quando os materiais orgânicos são incorporados ao solo. $\mathrm{O}$ uso 
continuado de dejetos de suínos, principalmente a cama sobreposta, contribui para aumentar o estoque de $\mathrm{C}$ no solo, e esse efeito poderá ser ainda maior com a aplicação dos dejetos na superfície do solo.

\section{Conclusões}

1. A aplicação de dejetos de suínos com a palha de aveia não aumenta a mineralização do carbono presente na palha.

2. A incorporação dos dejetos de suínos e da palha ao solo provoca aumento na emissão de $\mathrm{CO}_{2}$ para a atmosfera, em comparação à manutenção desses materiais orgânicos na superfície do solo.

\section{Referências}

AITA, C.; CHIAPINOTTO, I.C.; GIACOMINI, S.J.; HÜBNER, A.P.; MARQUES, M.G. Decomposição de palha de aveia-preta e dejetos de suínos em solo sob plantio direto. Revista Brasileira de Ciência do Solo, v.30, p.149-161, 2006.

ANGERS, D.A.; RECOUS, S. Decomposition of wheat straw and rye residues as affected by particle size. Plant and Soil, v.189, p.197-203, 1997.

CHANTIGNY, M.H.; ROCHETTE, P.; ANGERS, A. Short-term C and $\mathrm{N}$ dynamics in a soil amended with pig slurry and barley straw: a field experiment. Canadian Journal of Soil Science, v.81, p.131137, 2001.

COPPENS, F. Water, carbon and nitrogen dynamics in soil: influence of crop residue location and quality. 2005. 203p. Thesis (Ph.D.) - Catholic University Leuven, Leuven.

EMBRAPA. Sistema brasileiro de classificação de solos. Brasília: Embrapa-SPI; Rio de Janeiro: Embrapa-CNPS, 1999. 412p.

FLESSA, H.; BEESE, F. Laboratory estimates of trace gas emissions following surface application and injection of cattle slurry. Journal of Environmental Quality, v.29, p.262-268, 2000.
KERMARREC, C. Bilan et transformations de l'azote en élevage intensif de porcs sur litière. Rennes. 1999. 186p. Thèse (Docteur) - Université de Rennes 1, Rennes.

KIRCHMANN, H.; LUNDVALL, A. Relationship between N immobilization and volatile fatty acids in soil after application of pig and cattle slurry. Biology and Fertility of Soils, v.15, p.161-164, 1993.

PAUL, E.A.; CLARK, F.E. Soil microbiology and biochemistry. 2.ed. San Diego: Academic Press, 1996. 340p.

RECOUS, S.; ROBIN, D.; DARWIS, D.; MARY, B. Soil inorganic N availability: effect on maize residue decomposition. Soil Biology and Biochemistry, v.27, p.1529-1538, 1995.

REICOSKY, D.C.; ARCHER, D.W. Moldboard plow tillage depth and short-term carbon dioxide release. Soil Tillage Research, v.94, p.109-121, 2007.

REINERTSEN, S.A.; ELLIOTT, L.F.; COCHRAN, V.L.; CAMPBELL, G.S. Role of available carbon and nitrogen in determining the rate of wheat straw decomposition. Soil Biology and Biochemistry, v.16, p.459-464, 1984.

ROCHETTE, P.; ANGERS, D.A.; CHANTIGNY, M.H.; BERTRAND, N.; CÔTÉ, D. Carbon dioxide and nitrous oxide emissions following fall and spring applications of pig slurry to an agricultural soil. Soil Science Society of America Journal, v.68, p.1410-1420, 2004.

SAVIOZZI, A.; LEVI-MINZI, R.; RIFFALDI, R.; VANNI, G. Role of chemical constituents of wheat straw and pig slurry on their decomposition in soil. Biology and Fertility of Soils, v.25, p.401406, 1997.

SOMMER, S.G.; HUSTED, S. The chemical buffer system in raw and digested animal slurry. Journal of Agricultural Science, v.124, p.45-53, 1995.

STOTZKY, G. Microbial respiration. In: BLACK, C.A. (Org.). Methods of soil analysis. Madison: American Society of Agronomy, 1965. v.2. p.1550-1572.

TEDESCO, M.J.; GIANELLO, C.; BISSANI, C.A.; BOHNEN, H.; VOLKWEISS, S.J. Análises de solo, plantas e outros materiais. 2.ed. Porto Alegre: UFRGS, 1995. 174p. (Boletim Técnico, 5).

Recebido em 3 de julho de 2007 e aprovado em 12 de dezembro de 2007 